\title{
THE DAR AL CONSUL COMPLEX IN JERUSALEM: IMPROVING THE LIVING CONDITIONS AND THE STRUCTURAL CAPACITY
}

\section{FILIPPO CASARIN ${ }^{1 *}$, LEONARDO DI MARCO ${ }^{2}$, MARCO MOCELLINI $^{1}$, RAMZI SIDAWI ${ }^{2}$, PHILIP DAHABREH ${ }^{2}$ AND AMJAD K. TAWEEL ${ }^{3}$}

\author{
${ }^{1}$ Expin srl - Spin-off of the University of Padua \\ Via Pisacane 34, 35138 - Padova, Italy \\ email: casarin@expin.it, http://www.expin.it (*corresponding author) \\ ${ }^{2}$ Custodia Terrae Sanctae \\ St. Saviour's Monastery, P.O.B. 1869100101 Jerusalem \\ email: technical_office@custodia.org, https://www.custodia.org \\ ${ }^{3}$ UN-Habitat - Special Human Settlements Programme for the Palestinian People \\ Ramallah, UCI Building, 17 Nizar Qabbani Street, Al-Masyoun \\ email: amjad.taweel@un.org, https://unhabitat.org/
}

Keywords: Jerusalem, Historical Structure, Masonry, Investigation techniques

\begin{abstract}
The Custody of the Holy Land, with own and EU funds, and in Partnership with UNHabitat, is implementing a comprehensive rehabilitation Project in Dar Al Consul civic and residential complex, which is one of the Custody properties in the heart of the Old City of Jerusalem. The complex, which corresponds to a urban block of relevant dimensions $(80 \times 50$ $m \times 5$ levels above and below the ground) and intersects the Roman Cardo, consists of 40 Houses and a basement floor used as a closed storage at the street level, besides sharing part of its ground floor with the old city market. Prior to the planned rehabilitation works in the houses - to improve the living conditions - and in the basement - to be reused as public space - the Custody intended to conduct a safety assessment of the complex for both static and seismic loads, in order to integrate any needed strengthening work within the planned restoration activities. A series of technical activities were then carried out aimed at evaluating the safety conditions of the structures. A comprehensive investigation campaign was planned and executed in order to characterize the structural materials and define the constructive techniques. Several modelling strategies of the structures, which resulted particularly complex for the historical stratification of the site, were then used. By means of numerical modelling, the stresses were defined in the masonry elements by weight and by occurrence of a seismic event, allowing to highlight the insufficient safety conditions of the main resisting elements of the basement and subsequently to define adequate structural consolidation strategies. During the works, the need for archaeological excavation implied further engineering efforts in order to allow deep excavations avoiding any harm to the above positioned levels and structural portions.
\end{abstract}




\section{FOREWORD}

The Custody of the Holy Land is a fraternity of the Order of Friars Minor, a religious order in the Catholic Church, the Franciscans. The Custody preserves, studies and values the places where the Christian faith originated. It also provides social and housing services to the communities who live in the Holy Land. The Custody, in partnership with UN-Habitat and with own and UE funds, is implementing a comprehensive rehabilitation project in the Dar al Consul civic and residential complex, which is one of the Custody properties in the Old city of Jerusalem. Such complex consists of 40 houses and a basement floor used - at the beginning of the works - as a closed storage at the street level. The project intends to rehabilitate the houses to improve the living conditions of the local community, upgrade the open spaces among the houses and to rehabilitate and confer a new use to the basement as a public space [1].

The building complex covers about 2' 400 sq. m divided into 6 buildings, bounded by Khan El Zeit Street, where there are shops of the Jerusalem Souk, and El Tikkyeh Street, where the entrances are. The height of the buildings is variable and reaches a maximum of about $15 \mathrm{~m}$ from the street level, with 3 floors besides the basement floor (Figure 1).

In parallel with the intended aims of the project, the Custody requested a thorough study for understanding the structural behavior of the built environment in order to couple the necessary rehabilitation interventions with the necessary structural strengthening actions.

2 SITE HIISTORY, "DAR AL CONSUL"

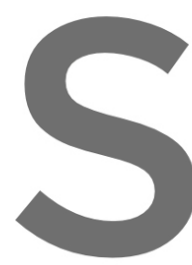

The building was nar middle of the $19^{\text {th }}$ centu the Muslim quarter to adjacent building that The property of the building
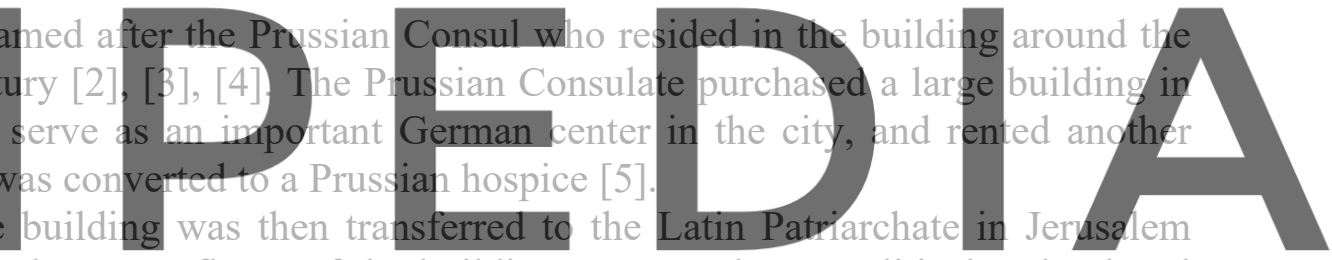

around the year 1882. The upper floors of the building were used as a political and cultural

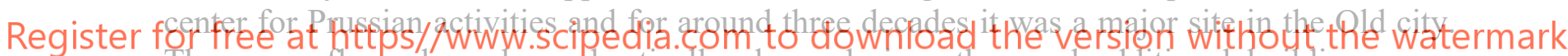
The upper floors have been drastically changed since then and additional buildings were constructed, changing the original shape. The building is one of a chain of huge buildings located on the eastern side of the Bab Khan az-Zait Market (Suq Khan az-Zait). The current extension of the Khan az-Zait Market can be traced back to the second century AD.
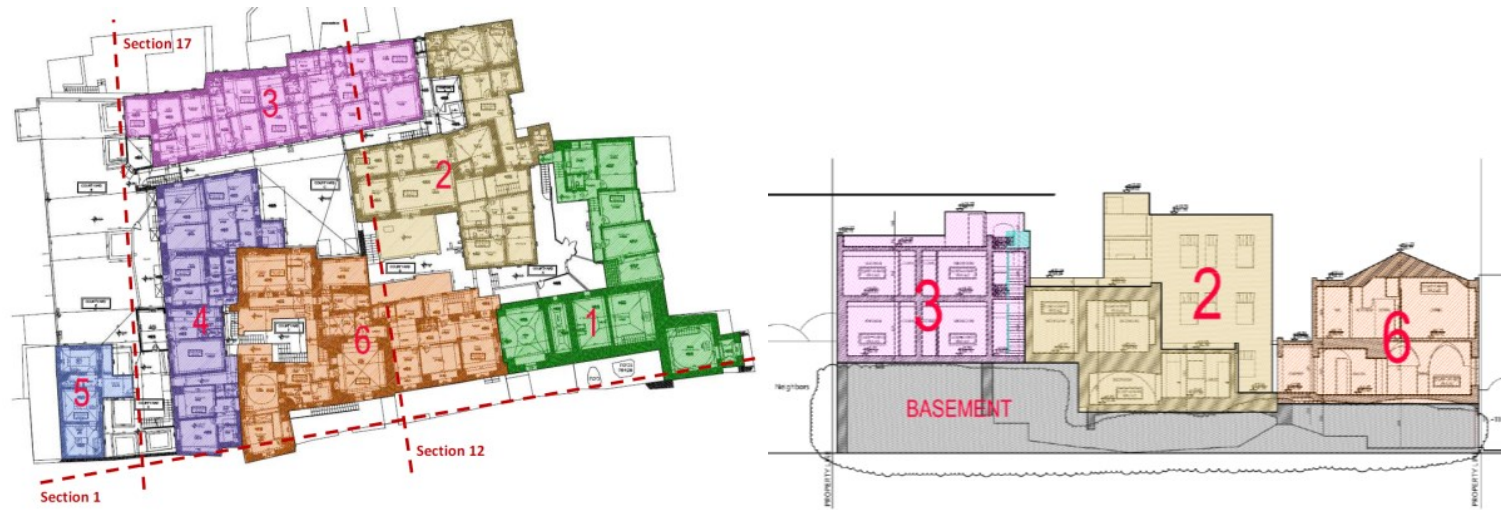

Figure 1: plan view and cross section of the Dar al Consul structural complex in the old city of Jerusalem 

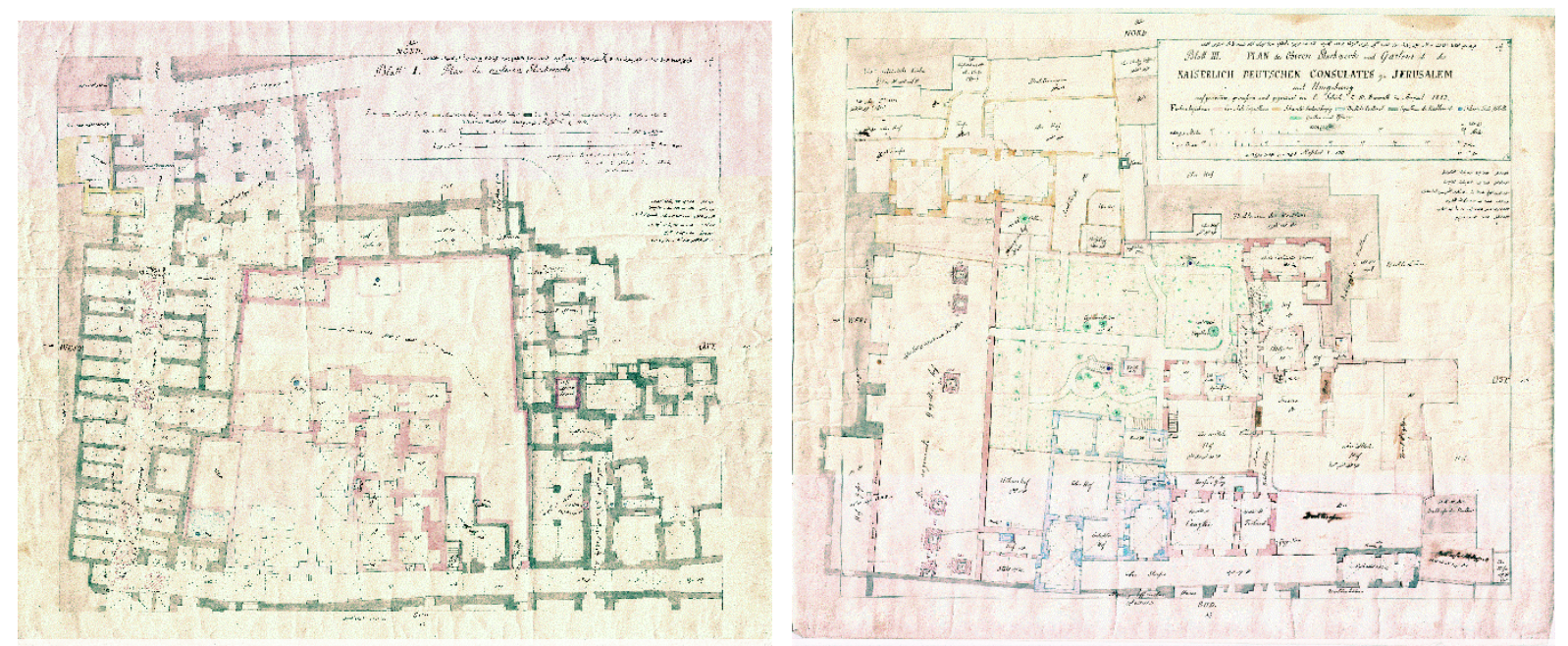

Figure 2: Architectural plans of the building dated August 1882 and January 1883, C.Schick - K.W.Baurath,

This was part of the Cardo Maximus, constructed by the Roman Emperor Hadrian as the main colonnade street of "Aelia Capitolina" (the roman name for Jerusalem) in the second century AD. The whole Suq Khan az-Zait and the eastern alleys connected to it were engaged in soap production as well as several olive-oil and sesame presses (ma'asir simsim). These kinds of productions can be traced back to the $10^{\text {th }}$ century AD., or even earlier. It seems that the

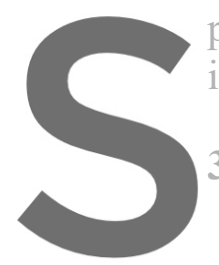
production of soap had also continued in the C.
in both the Mamluk and the Ottoman periods.
3 STRUCTURAL INVIESTIGATIONS
From the $1^{\text {st }}$ to the $5^{\text {th }}$ of December 2014 , a From the $1^{\text {st }}$ to the $5^{\text {th }}$ of December 2014, a wide expe
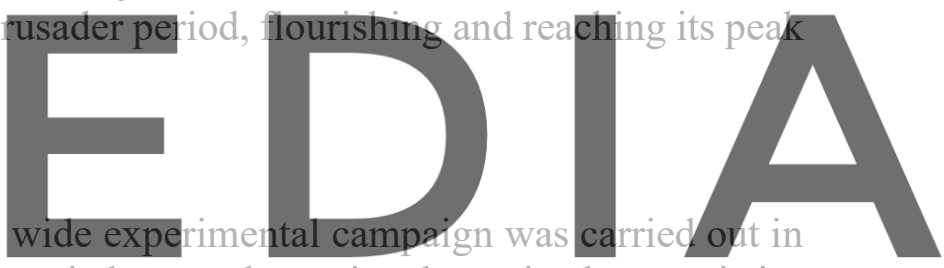

the Dar Al Consul site [6]. The campaign was carried out to determine the main characteristics

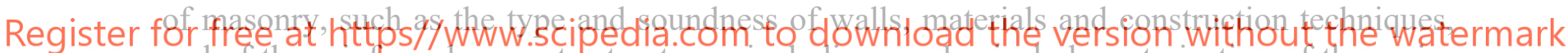
and of the reinforced concrete structures, including mechanical characterization of the major

structural elements. Several non-destructive and slightly destructive tests were performed on masonry walls and columns, such as single and double flat jack tests to obtain information on the mechanical characteristics of masonry, sonic tests to identify the compositional characteristics of masonry by measuring the velocity of mechanical waves propagating within the structural elements, videoscope surveys to determine the constitution of the structural elements and the material features, mortar and stone collection for laboratory tests aimed at the determination of their chemical-physical-mechanical properties, providing useful information on the analyzed structural materials. Also tests on reinforced concrete elements of the XX c. buildings were performed, including magnetometric surveys with covermeter aimed at the determination of the position of the rebars in the r.c. elements, with estimation of the concrete cover of the reinforcement, Schmidt-hammer together with ultrasonic tests, aimed to the estimation of the characteristics of the concrete with the SonReb method, compressive strength tests on concrete cores extracted, tensile testing of samples of reinforcing bars in laboratory aimed at the determination of the mechanical characteristics of the steel. 


\subsection{Obtained results}

Results obtained from the tests carried out highlighted a marked vulnerability of the substructures of the complex, and acceptable mechanical characteristics of the structural elements in the upper floors, especially of the most recent buildings.

According to the visual surveys, the masonry typology of the basement may correspond to "Masonry with roughly arranged stones, made up with external leaves of limited thickness and internal infill" (table C8A.2.1, [8]), with Young modulus E - to be considered for stability calculations - in the range 1'020-1'440 N/mm². The comparison with the obtained results shows that the modulus of elasticity in the unloading branches is similar, even if quite scattered, for several tests carried out. However, in the loading branch calculation, a visible stiffness reduction is evident for low value of compressive stress, denoting a reduced value with respect to similar masonry typology found in the area [7]. Moreover, the sampled mortar is remarkably poor and with a substantial presence of organic material.

Sonic tests indicate generally reduced values, especially those carried out in the basement. The walls denoted to have quite low sonic velocities on the ground floor, possibly indicating reduced mechanical characteristics and/or presence of internal loose infill, cavities or inconsistencies. In the upper level velocities are higher, however with variable velocity values. Velocity remarkably increase in presence of diatones or other stones that cover the entire thickness of the wall.
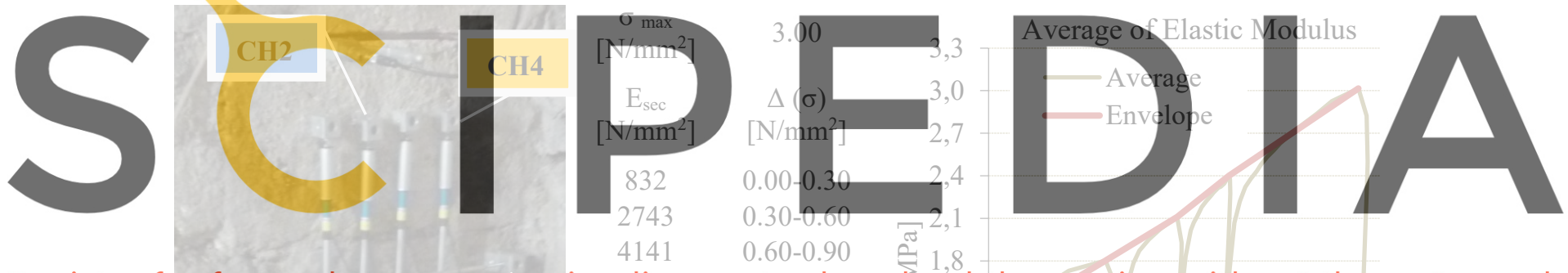

Register for free at https//www.scipedia.comp.to- downtoad the version without the watermark

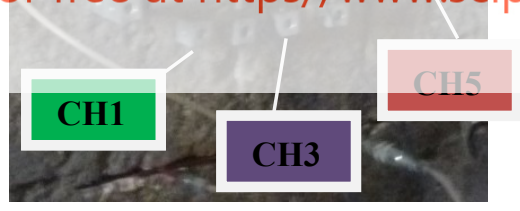

Sensors' layout - test FJ2
$487 \quad 1.20-1.50$

$158 \quad 1.50-1.80$

160

208

177

1.80-2.10

2.10-2.40

2.40-3.00
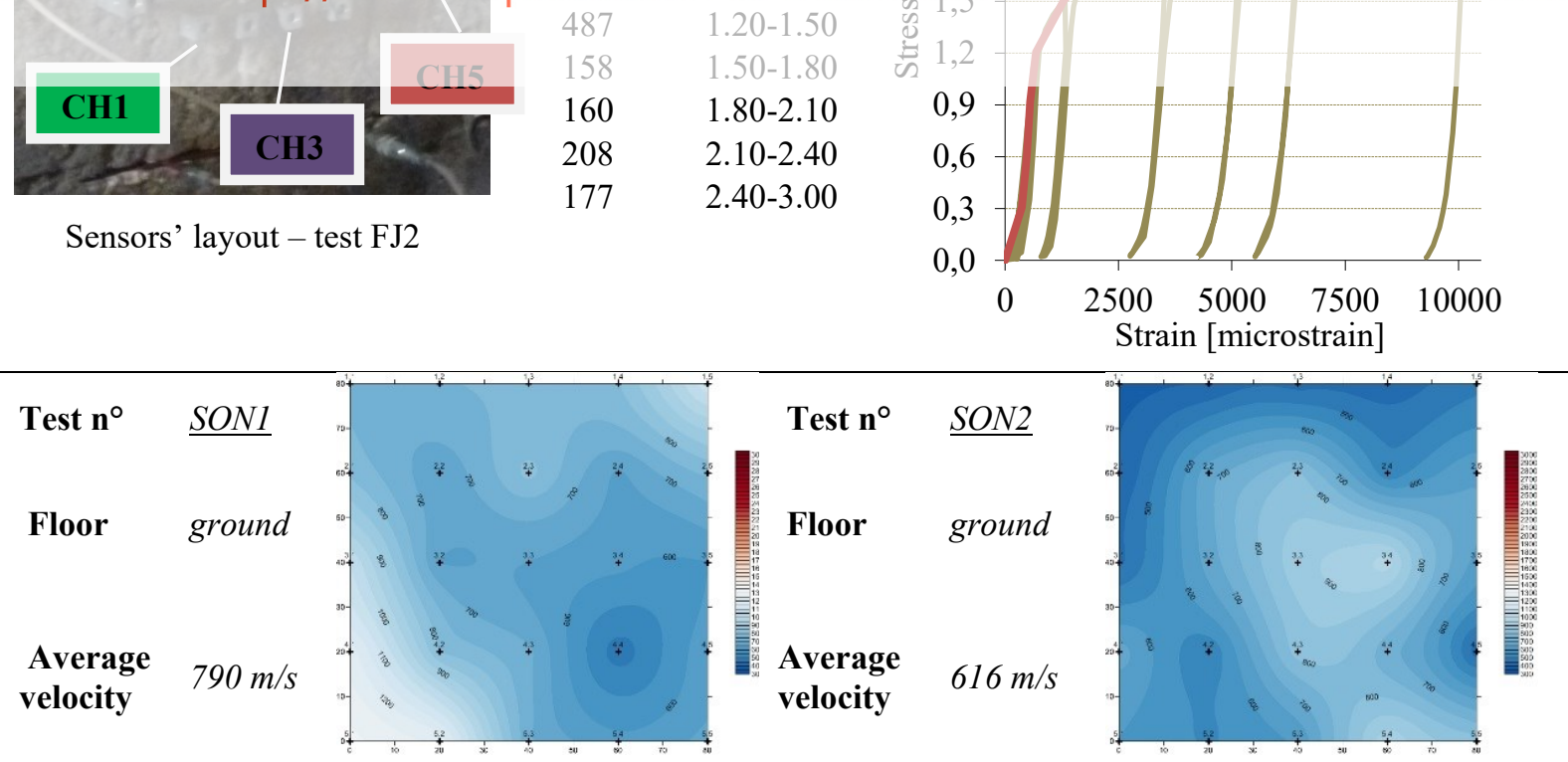

Figure 3: investigation campaign results, basement: (above) Flat Jack test nr.2; (below) sonic tests SON 1 \& 2 
Direct visual inspections executed through video endoscopy on masonry elements made possible to identify the inner characteristics of walls, floors and vaults, indicating different state of material compactness and arrangement for the several surveys carried out. The surveys allowed the direct inspection of the inner composition of walls, mainly composed by stone masonry with joints of considerable size.

\section{STRUCTURAL MODELING - SAFETY CONDITIONS}

\subsection{The modeling strategy}

Considered the structural complexity of the site, a multi-modelling approach was chosen, trying to overcome the limits of any modelling strategy by a combination of methodologies, relying on both global and local models. Linear FE modelling is considered a reliable procedure for the definition of the vertical stress distribution (self-weight analysis) on masonry structures, since the Finite Elements method allows modelling very complex geometries in a quite precise manner. Limits of this methodology emerge when performing the seismic analysis, introducing remarkable shear and tensile stresses, given the (fictitious) hypothesis of linear behavior of structural materials. For this reason and in general in historic masonry buildings, dynamic linear analyses should be more used for understanding the general dynamic behavior (initial frequencies, mode shapes, relevant areas from a dynamic point of view...) rather for defining the structural safety at the Ultimate Limit State. A non-linear equivalent frame approach is indeed suggested for the (pushover) analysis, since th the strongly non-linea accordingly, even if acer analysis is considered the seismic response
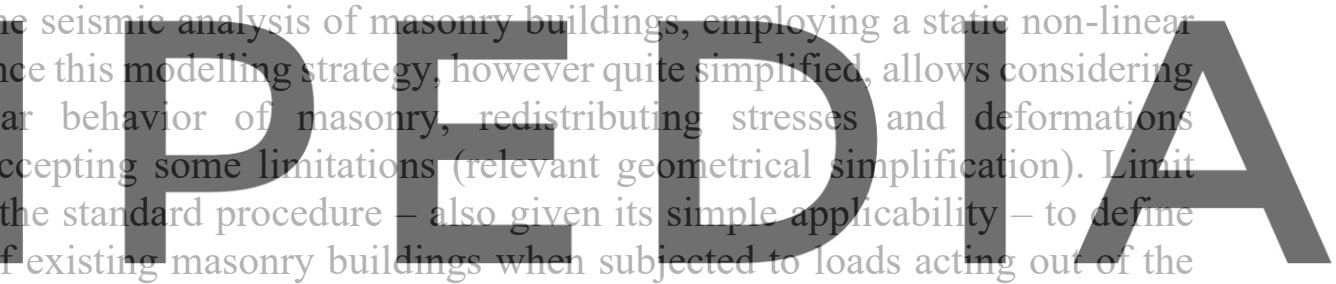
plane of the resisting masonry panels, being the most relevant damage scenario experienced by

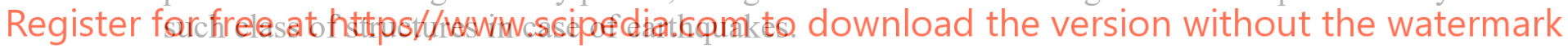
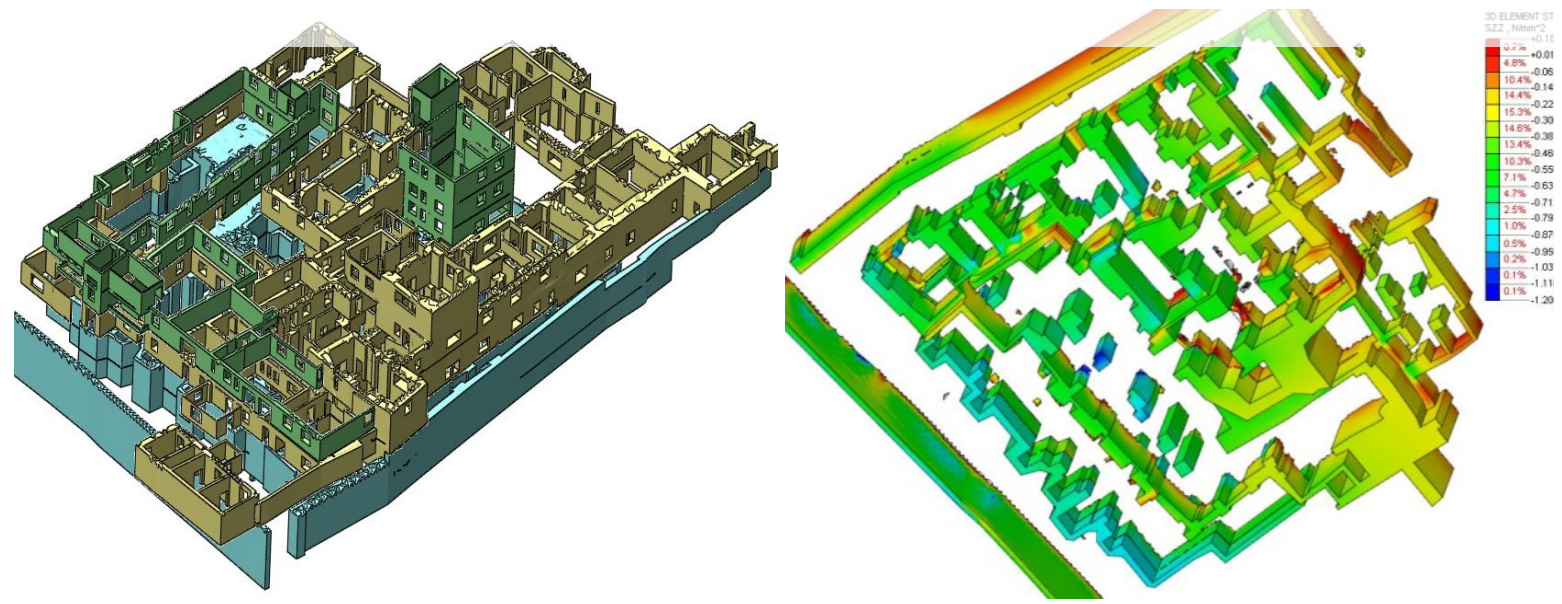

Figure 4: the Dar al Consul global FE model (left) and results of the self-weight analysis at the basement (right) 
For the definition of the structural safety level of the Dar al Consul site, the following analysis methodologies were then used: Numerical modelling (Finite Element method), for the assessment of the static and seismic response of the whole complex, by using a static and modal (seismic response) analyses. Numerical modelling (Equivalent Frame approach), for the evaluation of the seismic response of the most significant portions of the residential buildings. Limit analysis, for the ULS safety evaluation of individual structural portions resisting by equilibrium conditions to the seismic inertial forces.

\subsection{Obtained results}

A tridimensional FE model of the Dar al Consul structural complex was created in order to evaluate the stress and deformation patterns in the masonry and concrete elements [9]. The model is bounded to the ground with fixed restraints, and it is composed by 430'291 tetrahedral $3 \mathrm{D}$ elements and 891 beams. The typical size of the tetrahedral 3D element is $0,5 \mathrm{~m}$.

The self-weight analysis was carried out according to the Israeli Standard SI 412 basic combination [10]. Results obtained in terms of $\sigma_{z Z}$ stress (compression) indicate that the average value of compressive stress at the ground (basement) level corresponds to approximately $0,5-0,6 \mathrm{~N} / \mathrm{mm}^{2}$. In the upper floors the stresses decrease to $0,25-0,35 \mathrm{~N} / \mathrm{mm}^{2}$. The maximum compressive stress locates at the basement level, where the poorest masonry quality was found, in the main pillars supporting building nr.4. An average compressive stress of approximately $1,0 \mathrm{~N} / \mathrm{mm}^{2}$ or slightly higher is found in the pillars subject to higher

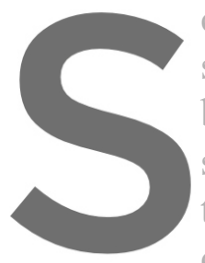
compressive forces. Considered the reduced nas
stability checks carricd out, unsafe conditions
basement, namely the pillars sustaining the buid
subjected to less load but with possible lower stre
the analysis is in line with the material streng cracks / lack of maintenance d previous sticin
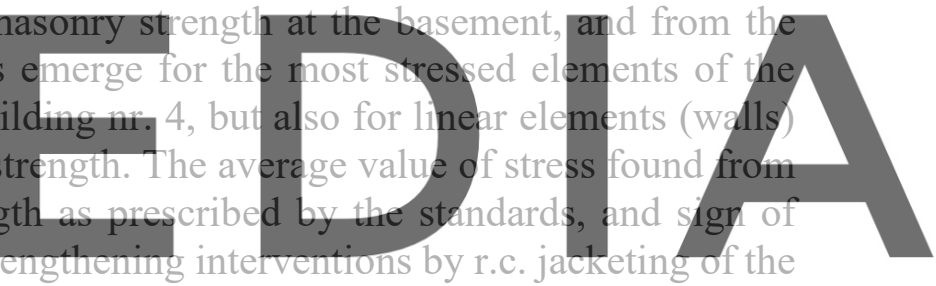
pillars - are present in this area, indicating this part of the complex as one of the most vulnerable

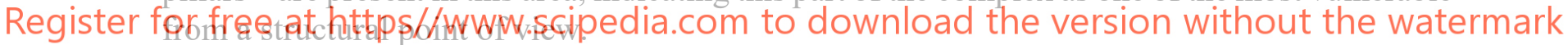

The seismic analysis of the Dar al Consul complex was carried out by using three different modeling strategies, relying on a numerical approach, with a linear (Finite Element Method) and nonlinear (Equivalent Frame) methodology, and on limit analysis, bearing in mind that the use of an elastic model for determining the seismic response of an existing masonry structure can be misleading since the stress redistribution following the relevant (real) non-linear material behavior in occurrence of an earthquake cannot be properly simulated.

In a first step, the FEM model proposed the analysis of the natural frequencies and associated modes of the structural complex, describing its linear dynamic behavior. The strong degree of compactness of the structural complex, as well as the confining action of the adjacent buildings, stiffen the structural dynamics of the complex, and only relatively few well identified modes were clearly identified, all of them related to the upper levels.

Results of the spectral response analysis, by employing the design response spectrum prescribed by the Israeli Standard SI 413 [11], indicate presence of non-negligible shear stresses in the masonry of the upper levels, following the mode shapes distribution. The shear values are however generally limited, reaching only in few points values non-compatible with the material strength, indicating possible damage concentration areas, in case of the design earthquake. 


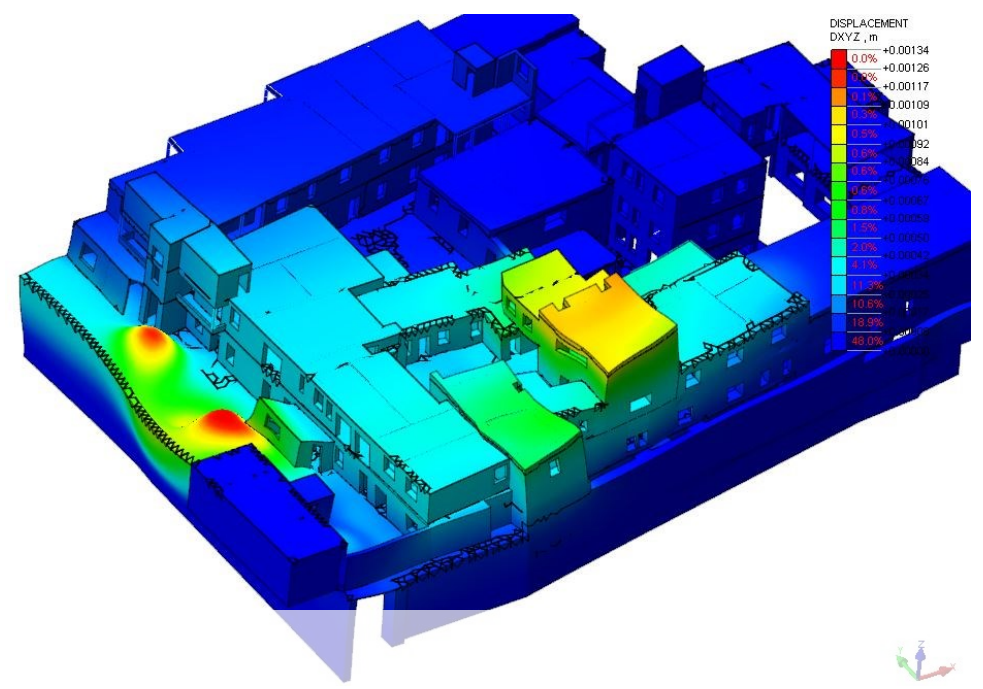

Figure 5: 3D FE model: a) mode $\mathrm{nr} .10-\mathrm{f}=6,10 \mathrm{~Hz}-31 \%$ of mass participation, dir.X

The large number of resisting walls in the two directions at the ground (basement) level together with the limited site seismic hazard, results in limited shear forces at the base of the complex.

Four Equivalent Frame (sub)models were implemented for the execution of the seismic analysis of the upper buildings of the structural complex, named building 1-6, building 2 building 3 and building 4. The analyses carried out per each sub-model indicate that the structural response can be considered adequate, by employing the elastic response spectram prescribed by the Israeli Standard SI 413 . How ever, considering the soil amplification factor as prescribed by the Italian Standard, it emerges that models building 1-6 and building 3 presen some deficiencies, mainly due to lack of resisting walls in the $Y$ direction, denoting a structura seismic vulnerability in the range of $70 \%$ (100\% corresponds to a satisfactory response).

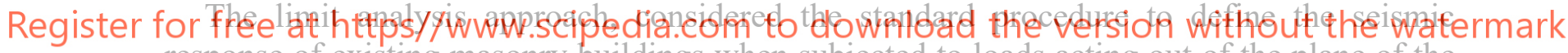
response of existing masonry buildings when subjected to loads acting out of the plane of the resisting masonry panels, was finally applied. The kinematic models, implemented to define the stability of the masonry panels under the seismic actions, were applied to a relevant number of masonry panels of the structural complex, whose stability was assessed in accordance with the Italian regulations, considering both linear and non-linear formulations [8].
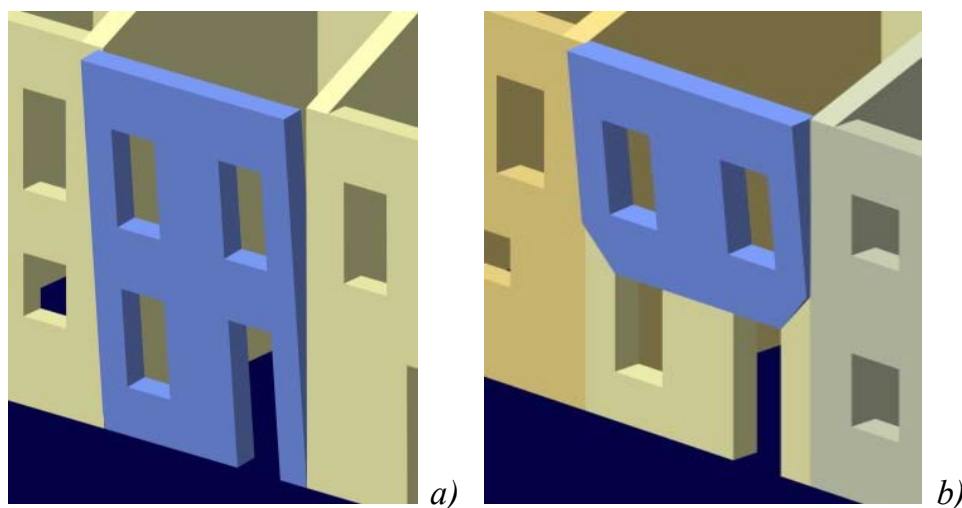

Figure 6: global overturning and upper overturning local collapse mechanism 
For each possible significant local mechanism, a part of the construction becomes a labile system (kinematic chain), through the identification of rigid bodies able to rotate between them (mechanism of damage or collapse), usually defined on the basis of typically seismic induced shear surfaces (cracks). The seismic action is then schematized as an equivalent static force given by the product of the mass of the wall and of the vertical loads, times the seismic acceleration, regarded as constant along the height of the wall. The procedure continues with the evaluation of the multiplier of loads (ratio of horizontal forces applied and weight of the masses) which activates the mechanism, that is to say that equals the stabilizing (loads of structural elements) and unstabilizing (inertial seismic) forces. Out-of-plane mechanisms relative to vertical strips of masonry were studied, involving the overturning of the whole wall (Figure $6 \mathrm{a}$ ) and of the upper level/s of the same wall (Figure $6 \mathrm{~b}$ ).

The checks indicate a general unsafe situation (see typical graphical representation in Figure 7), mainly for lack of adequate connection devices. The greater vulnerability corresponds to the presence of unrestrained vaults, domes and thin masonry in the upper floors of buildings, with their relevant horizontal thrust at the abutments.
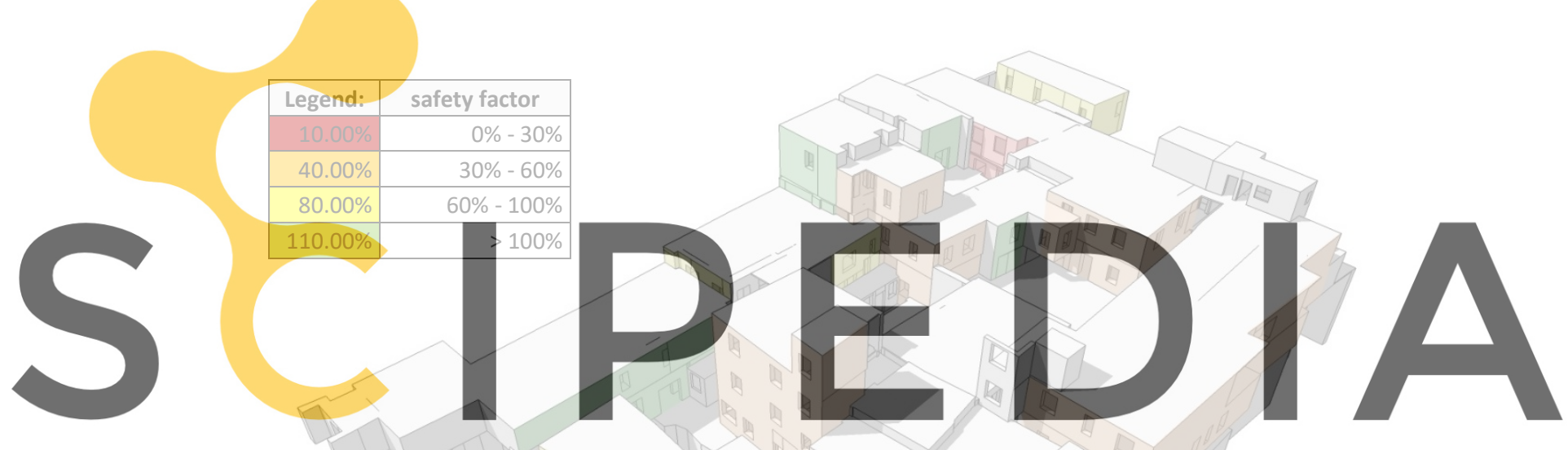

Register for free at https//www.scipedia.com to download the version without the watermark
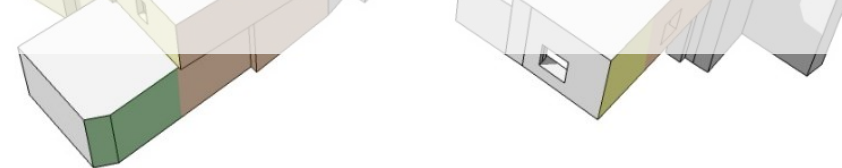

Figure 7: the Dar Al Consul complex North-East view, graphical representation of the safety factor

\section{THE REHABILITATION AND STRENGTHENING INTERVENTIONS}

A comprehensive architectural and structural intervention is being carried out since 2014, and it is still ongoing, entailing both the rehabilitation of the houses and public spaces of the complex and its structural strengthening and seismic upgrading. The interventions aim at upgrading the living conditions of the residential buildings in the upper levels, at the same time introducing elements for the seismic strengthening (e.g. tie beams), and to reconfigure and strengthen and preserve the basement spaces, that with the passing of time lost their residential / commercial function, finding a balance between conservation and changed architectural needs. Moreover, safety issues are further concerned considered the excavation needs of the site, for 
both functional and archaeological needs.

\subsection{Interventions in the basement}

It is noted a generalized lack of structural consistency in several areas of the basement resisting structures, for intrinsic reasons and for lack of maintenance interventions for relevant periods. The encountered masonry typology of the basement corresponds to irregular stone masonry, thus indicative of a structural vulnerability, worsened by the poor mortar quality. The results of the structural analysis indicated furthermore relevant stress values in the basement, especially in some vertical elements, where previous strengthening interventions were already introduced. For this reason it was considered critical - besides providing a generalized improvement of the mechanical characteristics of the stone masonry structures (hydraulic lime grout injections, deep repointing), to locally intervene to strengthen the most heavily loaded pillars, subjected to excessive compressive values with reference to the actual masonry capacity. Interventions such as "confinement" or "stitching" were designed and applied together with the overall interventions of hydraulic lime grout injections and deep repointing to provide an increased strength to such structures, consequently increasing their "safety" conditions.
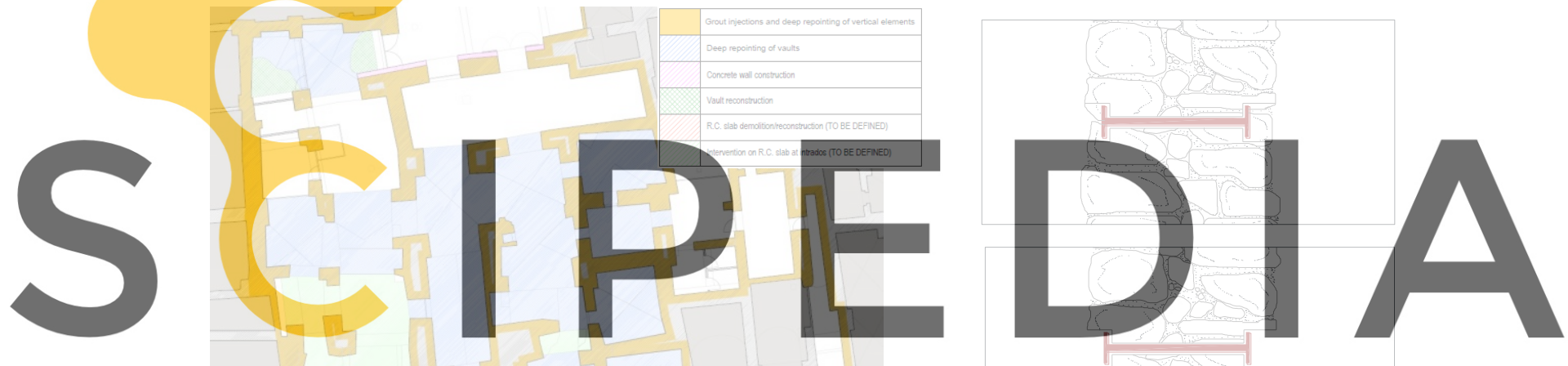

Register for free at https//www.scipedia.com to download the version without the watermark
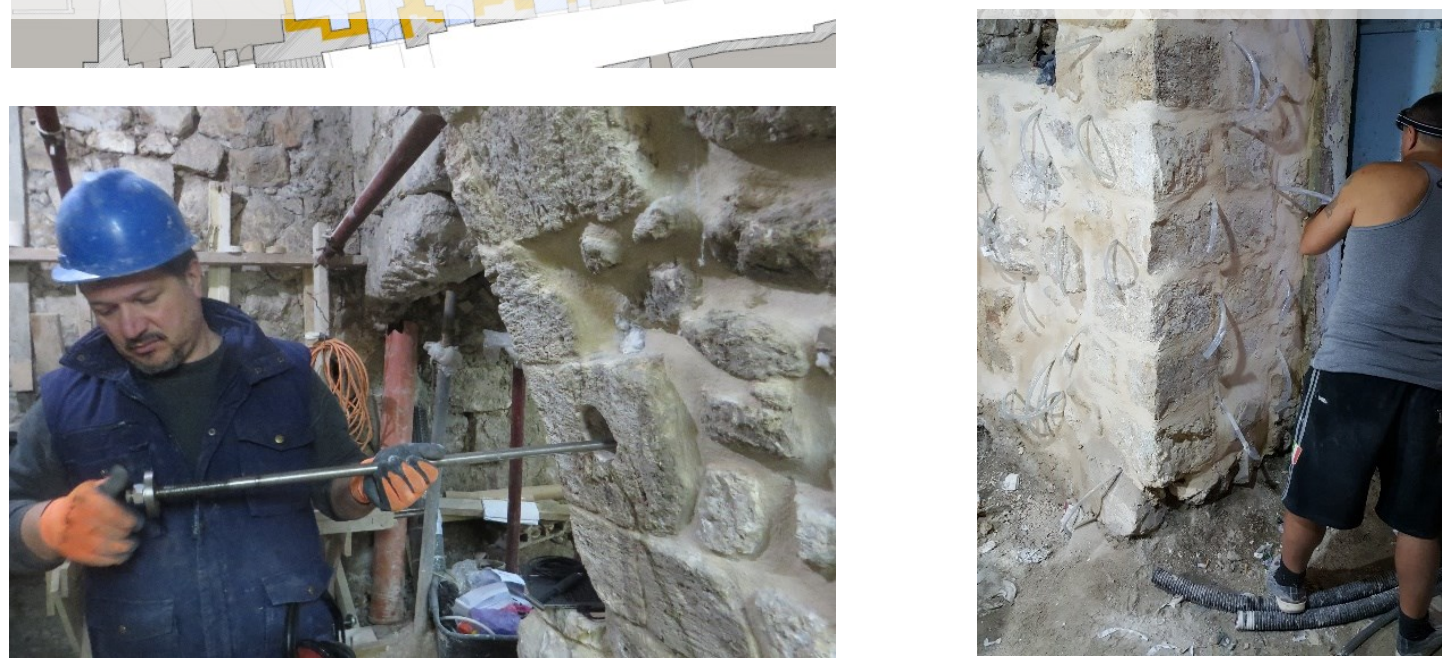

Figure 8: general layout of the interventions in the basement structures, strengthening intervention on pillars 

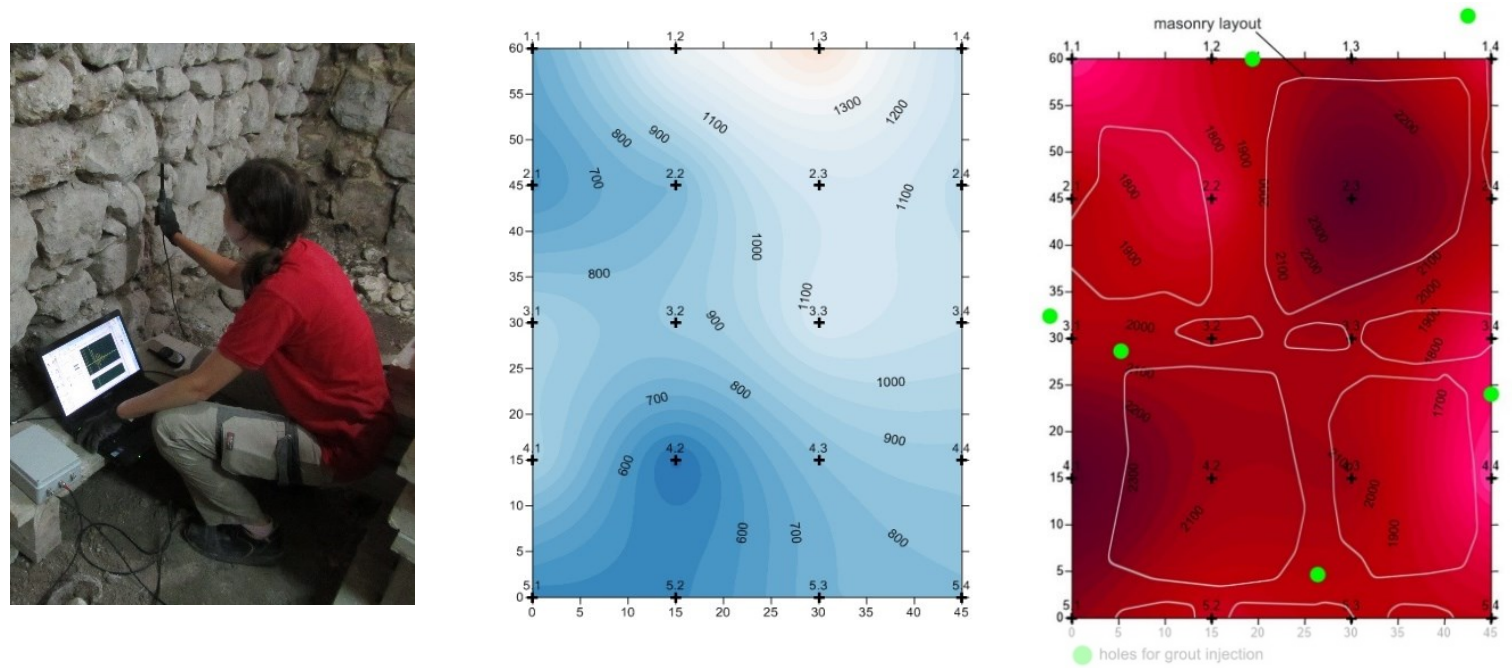

Figure 9: sonic test SON4/SON4i, comparison of velocity before (avg. $800 \mathrm{~m} / \mathrm{s}$ ) and after (avg. $2000 \mathrm{~m} / \mathrm{s}$ ) the injection intervention, graphic representation between sonic velocities (face view of the acquisition grid)

"Traditional" intervention methods were hence employed, always employing compatible materials as hydraulic lime mortar, as deep repointing in masonry walls and pillars, together with more recent techniques which proved their effectiveness, specifically in case of low

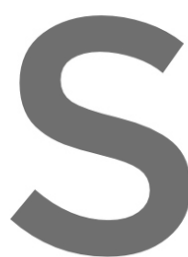
resistance stone masonry elements. Between these, grout injections in masonry wa pillars, executed with a high absorption widely found (in case of test SON4, an increase of 220\% was recorded). Other employed were the confinement of masonry pillars and walls transverse tying, in areas concentration, as emerged from the structural modelling. In cases in which there was tack of material, stone integration/reçonstruction was considered, highlighting the newly introduced Register fer free at bttps/gwWW.scipedia.com to download the version without the watermark
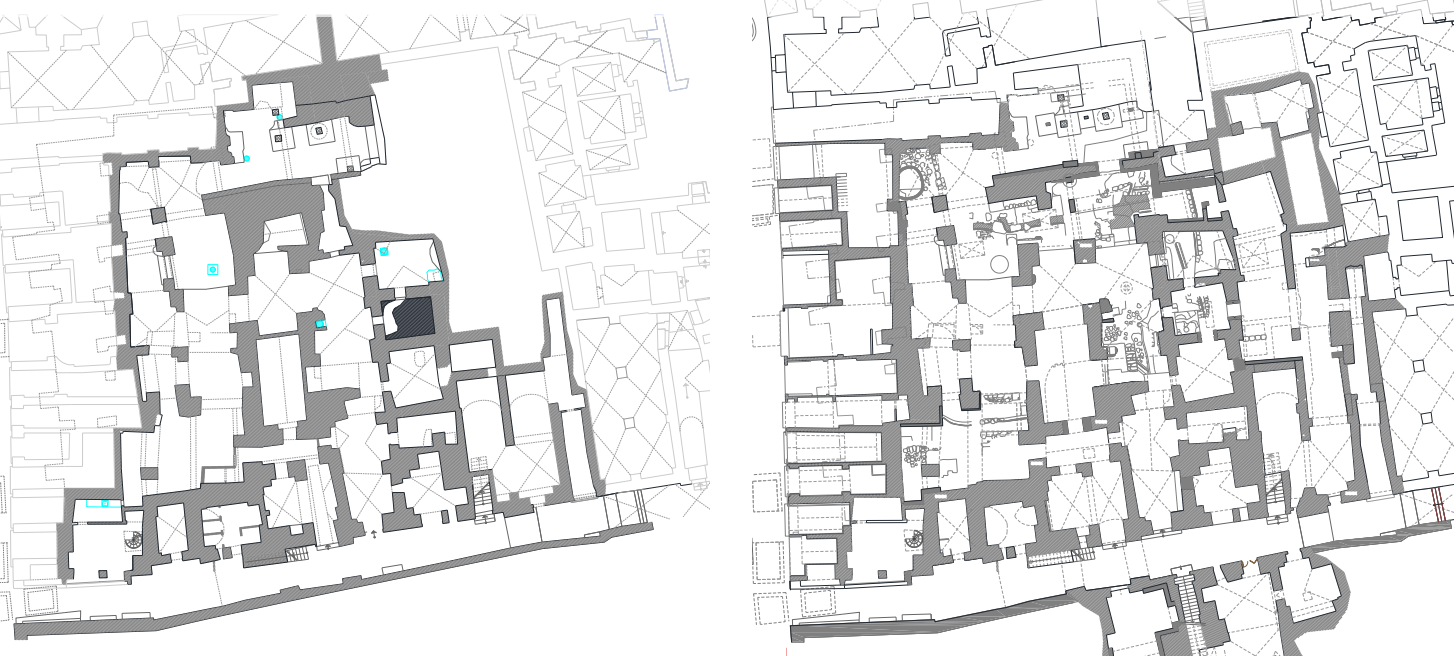

Figure 10: geometrical survey of the basement in 2014 (left) and today (right), with a relevant increase in area and excavations depth 
A relevant part of the activities finally corresponded to the excavations in the basement soil, which, year after year, gave the possibility to reach lower levels and find buried structures, also with relevant historical and archaeological findings (e.g. tombs, roman era shops), see Figure 10. From an engineering point of view, it was, and it still is a challenge to support the superstructures with uncertain soil conditions, given the difficult execution of geotechnical investigations, the diffuse presence of cisterns in the bedrock and the chaotic stratification of the historical layers of the underground Jerusalem.

\section{CONCLUSIONS}

- $\quad$ A wide study was carried out to define the structural safety levels of the Dar al Consul complex in Jerusalem. To this aim, several analytical methodologies were employed, since the assessment of the safety state of an historical masonry building is a remarkably complex task, and a single methodology may not be adequate to properly describe the structural response;

- A comprehensive on-site investigation campaign was carried out in order to characterize the resisting structures of the residential complex. Tests carried out highlighted the vulnerability of the masonry structures, especially in the basement;

- $\quad$ Several behavioral models of the structure were implemented, obtaining results of the linear FEM (static and dynamic), non-linear static (equivalent frame approach seismic), and linear and non-linear limit (local collapse mechanisms) analyses;

- $\quad$ The self-weight analysis indicates that the maximum compressive stress locates at the basement level, where the poorest masonry quality was found, in the main pillars supporting building $\mathrm{nr}$. 4 . An average compressive stress of approximately 1,0 N/mm2 or slightly above is found in the pillars subject to higher compressive forces. Considered the reduced masonry strength at the basement, and from the stability checks carried out, unsafe conditions emerge for the most stressed elements of the basement;

- $\quad$ Results of the seismic analysis indicate presence of non-negligible shear stresses in the masonry of the upper levels, following the mode shapes distribution. The shear forces are however generally limited, reaching only in few points values non-compatible with the material strength, indicating possible damage concentration areas, in case of the design earthquake. The large number of resisting walls in the two directions at the ground (basement) level together with the limited site seismic hazard, results in limited shear forces at the base of the complex.

- $\quad$ The strengthening intervention arising from the investigation and structural assessment phases, still ongoing, relies on traditional and present-day intervention methods, aiming at the material capacity increase (strengthening of masonry elements) especially in isolated elements or where high stress ratios are found;

- Activities in the Dar al Consul site are currently progressing towards completion, entailing - after the thorough structural strengthening phase - the architectural and conservative detailed design. 
Acknowledgements. The Dar al Consul Rehabilitation project is carried out through a partnership between the Custody of the Holy Land (site owner) and the UN-Habitat, with funds coming from the owner and the European Union.

\section{REFERENCES}

[1] Dar Counsel Rehabilitation Project Old city Analysis report STRUCTURAL ASSESSMENT Investigation and tests (2014) - unpublished

[2] Jubeh N. Dar al-Qunsul archaeological report (2015) - unpublished

[3] Arce, A. Ratisbonne y el santuario del Ecce Homo. Tierra Santa, tomo 33 - n. 354 (1958), p. 201

[4] Recio Veganzones, A. Dos inscripciones de Beyrouth conservadas en Jerusalén. Liber annuus 20 (1970), pp. 118-137

[5] Kark R. and Oren-Nordheim M., Jerusalem and its Environs, (2001), p. 58

[6] Casarin, F. Dal al Consul, Old City Jerusalem, EXPIN technical report - investigation campaign on the structures (2015) - unpublished.

[7] Casarin F. et al. (2019) Mechanical Characterization of Masonry Typologies in Israel via Flat Jack Tests. In: Aguilar R., Torrealva D., Moreira S., Pando M.A., Ramos L.F. (eds) Structural Analysis of Historical Constructions. RILEM Bookseries, vol 18. Springer, Cham

[8] Italian Technical Standards for Constructions, Ministerial Decree 17 jan 2018 and related explicative circular (Infrastructure \& Transportation Ministry) 21 jan 2019, n. 7

[9] Casarin, F. Dal al Consul, Old City Jerusalem, EXPIN technical report-structural analysis - current state (2015) - unpublished.

[10] Israel standard SI 413 - June 1995 - Design provisions for earthquake resistance of structures - The standards institution of Israel;

[11] Israel standard SI 412 - May 1992 - Loads on structures: characteristics loads - The standards institution of Israel; 